\title{
Three-Dimensional Pelvic Floor Ultrasound Assessment of Pelvic Organ Prolapse: Minimal Levator Hiatus and Levator Ani Deficiency Score
}

\author{
Yongwoo Yune, Hong Yoon Jeong, Duk Hoon Park, Jong Kyun Lee \\ Department of Surgery, Seoul Songdo Hospital, Seoul, Korea
}

Purpose: The purpose of this study was to determine whether levator ani deficiency (LAD) scores and minimal levator hiatus (MLH) areas affect Pelvic Organ Prolapse Quantification (POP-Q) stage.

Methods: This study was a retrospective chart review of patients with pelvic organ prolapse (POP) at Seoul Songdo Hospital between August 2019 and August 2020. Three-dimensional (3D) pelvic floor ultrasound, preoperative anal manometry, and other physiological tests were performed in 78 patients with POP symptoms. We divided the patients into mild prolapse and severe prolapse groups based on the POP-Q. We examined the LAD and MLH areas. LAD scores were categorized as mild, moderate, or severe.

Results: There were 32 patients (41.0\%) in the mild prolapse group (POP-Q stage I and II) and $46(59.0 \%)$ in the severe prolapse group (POP-Q stage III and IV). The mean LAD score was significantly higher in severe prolapse group (13.33 \pm 2.49 vs. $8.19 \pm 2.92, \mathrm{P}<0.001$ ), and the rate of severe deficiency was also significantly higher in the severe prolapse group (29 [63.0\%] vs. 2 [6.3\%], $\mathrm{P}<0.001)$. The mean MLH was also significantly larger in the severe prolapse group (17.91 $\pm 2.74 \mathrm{~cm}^{2}$ vs. $\left.14.95 \pm 2.60 \mathrm{~cm}^{2}, \mathrm{P}<0.001\right)$. In addition, both MLH and LAD scores tended to increase at each stage.

Conclusion: There is a strong positive correlation between the POP-Q stage and the MLH and LAD scores that can be seen on 3D pelvic floor ultrasound. The findings of this study, by objectively demonstrating LAD and MLH in women with POP, are an important contribution to POP.

Keywords: Pelvic organ prolapse; Pelvic floor; Ultrasonography; Minimal levator hiatus; Levator ani deficiency score

\section{INTRODUCTION}

Pelvic organ prolapse (POP) is a common condition that occurs in up to $40 \%$ of the female population aged between 45 and 85 years [1]. POP is symptomatic in up to $20 \%$ of patients and affects women's quality of life by causing discomfort as well as urinary, sexual, and defecation dysfunction $[1,2]$. In particular, the inci-

Received: Dec 28, 2020 • Revised: Mar 6, 2021 - Accepted: Mar 16, 2021 Correspondence to: Hong Yoon Jeong, M.D.

Department of Surgery, Seoul Songdo Hospital, 72 Dasan-ro, Jung-gu, Seoul 04597, Korea

Tel: +82-2-2250-7368, Fax: +82-2-2233-8528

E-mail:Vishnujin84@gmail.com

ORCID: https://orcid.org/0000-0002-2385-6069

(C) 2021 The Korean Society of Coloproctology

This is an open-access article distributed under the terms of the Creative Commons Attribution NonCommercial License (https://creativecommons.org/licenses/by-nc/4.0) which permits unrestricted noncommercial use, distribution, and reproduction in any medium, provided the original work is properly cited. dence of POP in women is significantly increased by vaginal childbirth [3]. A previous study suggested a 5 -fold increase in the odds of POP 5 to 10 years after vaginal birth compared to cesarean delivery [4]. Although the reason for this change is not clear, recent studies have explored the relationship between obstetrical levator injuries, levator hiatus size, and prolapse $[5,6]$. Levator ani deficiency (LAD) contains levator ani muscle (LAM) avulsion, which means that the levator muscle is detached from its origin at the pubis. These LADs are observed in $10 \%$ to $30 \%$ of vaginal deliveries $[7,8]$. It is also significantly associated with the development of POP later in life $[9,10]$. LAD appears to lead to a significantly large levator hiatus [11]. However, it is unknown whether this change in levator structure could explain the development of POP after vaginal childbirth.

The Pelvic Organ Prolapse Quantification system (POP-Q) addresses the extent to which prolapse protrudes beyond the hymenal ring. The POP-Q and ordinal stages were introduced in 
1996 as a more valid staging system than the Baden-and-Walker system, dating from 1972 [12]. Translabial 2-dimensional (2D) ultrasound prolapse assessment was first described in 2001 and has a good correlation with the POP-Q system $[13,14]$. However, there is a second element of prolapse caused by the descent and ballooning of the levator ani and perineal structures $[15,16]$. Furthermore, pelvic floor descent is associated with visible tears in the levator muscle [17]. With the help of 3-dimensional (3D) ultrasound imaging, it is possible to obtain information on anatomical abnormalities of the levator muscle and hiatus [18]. Birth-induced injury to the pubovisceralis (PV) muscle portion of the LAMs is strongly associated with POP $[6,9,19]$ and downward displacement of the perineal structures [20]. Because the minimal levator hiatus (MLH) measures the inner side of the puborectalis (PR), these injuries are also related to MLH.

A 3D pelvic floor ultrasound is an examination that has many advantages for POP patients because it is fast, effective, noninvasive, and well-tolerated. Until now, data showing the relationship between LAD scores and MLH areas using 3D pelvic floor ultrasound and POP-Q stage is insufficient. The purpose of this study was to determine whether LAD scores and MLH areas affected POP-Q stage.

\section{METHODS}

This study was a retrospective chart review of patients with POP at Seoul Songdo Hospital between August 2019 and August 2020. A total of 78 patients with symptoms of POP symptoms, such as sensation or visualization of a vaginal lump. All 3D pelvic floor ultrasounds were performed by an experienced pelvic floor colorectal surgeon. This study was approved by the Institutional Review Board of Seoul Songdo Hospital (No. 2020-012). Informed consent from patients was waived because of the retrospective nature of the study.

Our assessment included a medical history examination and questionnaire scores for constipation and fecal incontinence. This preoperative questionnaire included the Cleveland Clinic Constipation Scoring System (Wexner constipation score), Cleveland Clinic Incontinence Score (CCIS, Wexner incontinence score), Fecal Incontinence Severity Index (FISI), and Fecal Incontinence Quality of Life (FIQOL) scale [21, 22]. Patients who underwent perineal repair or sphincteroplasty were excluded. The examination consisted of a 3D ultrasound device (Flex Focus Endoprobe model 8838, B-K Medical, Herlev, Denmark). Ultrasound was performed in the supine position and immediately after voiding. All ultrasound images were acquired according to the 5 steps of Shobeiri et al. [23]. Only those with complete data and high-quality ultrasound scans were included. In addition, all patients underwent preoperative anal manometry and other physiological tests. Pelvic floor disorders were also diagnosed based on the American Society of Colon and Rectal Surgeons (ASCRS) guidelines [24].
For POP-Q staging, the anterior and posterior walls of the vagina, cervix, and uterus were determined in centimeters above or below the hymen on maximum Valsalva maneuver [24]. Prolapse grades were assigned based on the degree of prolapse in relation to the hymen. These stages were defined according to the ASCRS guidelines [24]. We divided the patients into mild prolapse groups for POP-Q stages 0 to 2 and severe prolapse groups for POP-Q stages 3 to 4 based on the most distal portion of the prolapsed organ being $1 \mathrm{~cm}$ or more beyond the hymen.

The 3D pelvic floor ultrasound images consisted of transperineal 2D functional images, endovaginal functional 2D images, endovaginal 3D images, and endoanal 3D images. In endovaginal 3D images, the MLH was measured by the method defined by Shobeiri et al. [25], and the LAD score was measured by the method defined by Morgan et al. [26]. The area of the MLH can be calculated as the area within the levator ani inner perimeter enclosed by the inferior pubic rami and the inferior edge of the symphysis (Fig. 1A). Morgan et al. [26] divided pelvic floor muscles into the puboanalis (PA), PV, and PR. Subgroups were evaluated and scored ( 0 , no defect; 1 , minimal defect; 2 , major defect; and 3 , total absence of the muscle) on each side based on the thickness and detachment from the pubic bone. LAD scores were categorized as mild ( $0-6$ points, Fig. $1 \mathrm{~B})$, moderate ( $7-12$ points), and severe (13-18 points, Fig. 1C) deficiency [27]. LAM avulsion was defined according to the minimal criteria for complete avulsion of
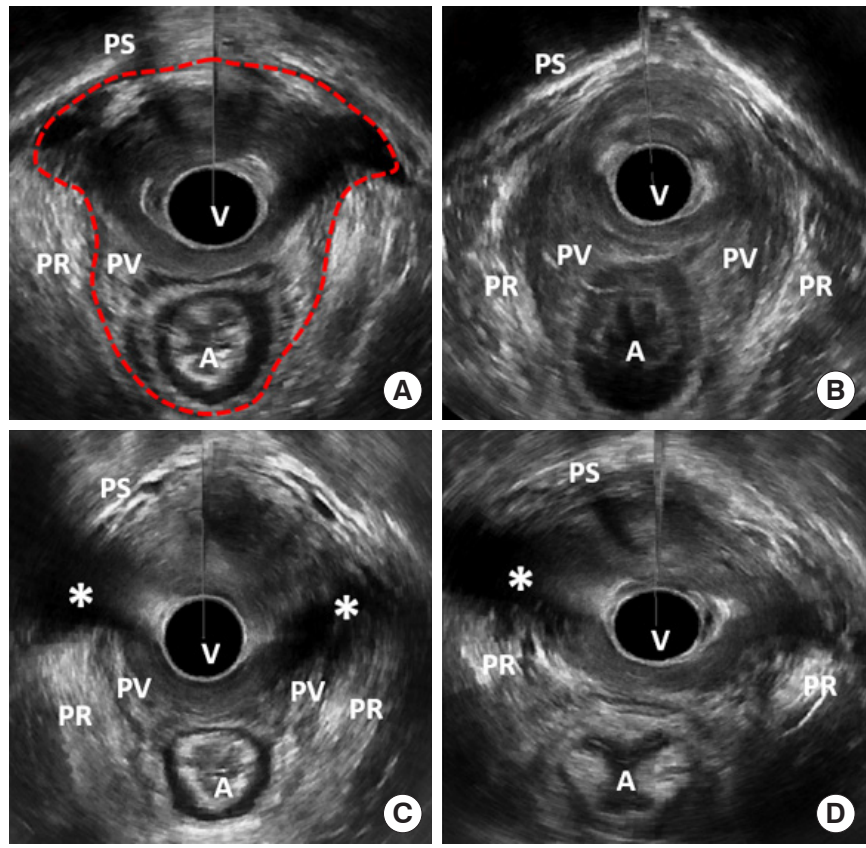

Fig. 1. Three-dimensional pelvic floor ultrasound images. (A) Minimal levator hiatus (MLH), (B) mild levator ani deficiency (LAD) score, (C) severe LAD score, (D) levator ani muscle avulsion. Red dotted line, MLH area; asterisk, avulsion site. A, anus; PR, puborectalis muscle; PS, pubic symphysis; $\mathrm{PV}$, pubovisceralis muscle; $\mathrm{V}$, vaginal. 
the LAM in at least 3 central slices obtained at the level of minimal hiatal dimension and $2.5 \mathrm{~mm}$ and $5 \mathrm{~mm}$ above [28] (Fig. 1D).

The numbers and percentages were reported for categorical variables, and the mean and standard deviation were reported for continuous variables. Significant differences between the mild prolapse and severe prolapse groups were determined using chisquare tests and independent 2-sampled t-tests. Statistical significance was set at $\mathrm{P}<0.05$. All statistical analyses were performed using IBM SPSS Statistics for Windows (ver. 22.0, IBM Corp., Armonk, NY, USA).

\section{RESULTS}

A total of 78 women were referred to our hospital with a chief complaint of POP during the study period. Eight women (10.3\%) had a history of hysterectomy, and 12 women (15.4\%) had already been managed with tension-free vaginal tape (Table 1). Overall, 17 (21.8\%), 15 (19.2\%), 26 (33.3\%), and 20 (25.6\%) had stage I, II, III, and IV POP, respectively. There were 32 patients $(41.0 \%)$ in the mild prolapse group (POP-Q stages I and II) and 46 (59.0\%) in the severe prolapse group (POP-Q stages III and IV). The groups were similar in terms of age, electromyography, and pudendal nerve terminal motor latency. However, patients in the severe prolapse group had a significantly high parity $(2.74 \pm 1.16$ times vs. $2.22 \pm 1.04$ times, $\mathrm{P}=0.046$ ). Patients who underwent all cesarean section deliveries were included in the severe prolapse group. In the severe prolapse group, pelvic floor symptoms such as CCIS (7.10 \pm 5.40 vs. $10.63 \pm 5.50, \mathrm{P}=0.028)$, FIQOL (14.98 \pm

Table 1. Patient characteristics and physiological test results

\begin{tabular}{|c|c|c|c|}
\hline Characteristic & Mild prolapse & Severe prolapse & P-value \\
\hline No. of patients & 32 & 46 & \\
\hline Age (yr) & $63.16 \pm 10.70$ & $66.96 \pm 11.66$ & 0.147 \\
\hline Parity (time) & $2.22 \pm 1.04$ & $2.74 \pm 1.16$ & 0.046 \\
\hline Type of parity & & & 0.006 \\
\hline Normal spontaneous vaginal delivery & $27(84.4)$ & $46(100)$ & \\
\hline Cesarean section & $5(15.6)$ & $0(0)$ & \\
\hline \multicolumn{4}{|l|}{ Previous operation history } \\
\hline Hysterectomy & $1(3.1)$ & $7(15.2)$ & 0.084 \\
\hline Tension-free vaginal tape & $4(12.5)$ & $8(17.4)$ & 0.556 \\
\hline Urinary incontinence & $11(34.4)$ & $22(47.8)$ & 0.255 \\
\hline \multicolumn{4}{|l|}{ Incontinence score (point) } \\
\hline CCIS & $7.10 \pm 5.40$ & $10.63 \pm 5.50$ & 0.028 \\
\hline FIQOL & $14.98 \pm 4.50$ & $11.23 \pm 3.21$ & 0.001 \\
\hline FISI & $18.45 \pm 16.45$ & $30.56 \pm 19.24$ & 0.024 \\
\hline \multicolumn{4}{|l|}{ Constipation score (point) } \\
\hline Wexner constipation score & $8.24 \pm 6.66$ & $12.95 \pm 5.28$ & 0.022 \\
\hline \multicolumn{4}{|l|}{ Anal manometry results } \\
\hline Maximal resting pressure (mmHg) & $57.57 \pm 14.98$ & $48.48 \pm 13.52$ & 0.012 \\
\hline Maximal squeezing pressure (mmHg) & $112.33 \pm 49.42$ & $102.43 \pm 55.05$ & 0.431 \\
\hline Electromyography & & & 0.342 \\
\hline Normal & $15(46.9)$ & $18(39.1)$ & \\
\hline Equivocal contraction & $15(46.9)$ & $20(43.5)$ & \\
\hline Paradoxical contraction & $2(6.3)$ & $8(17.4)$ & \\
\hline Pudendal nerve terminal motor latency & & & 0.402 \\
\hline Normal & $22(68.8)$ & $28(60.9)$ & \\
\hline Unilateral latency & $5(15.6)$ & $13(28.3)$ & \\
\hline Bilateral latency & $5(15.6)$ & $5(10.9)$ & \\
\hline
\end{tabular}

Values are presented as number only, mean \pm standard deviation, or number $(\%)$.

CCIS, Cleveland Clinic Incontinence Score; FIQOL, Fecal Incontinence Quality of Life; FISI, Fecal Incontinence Severity Index. 
Table 2. Three-dimensional pelvic floor ultrasound results

\begin{tabular}{lccc}
\hline Variable & $\begin{array}{c}\text { Mild prolapse } \\
(\mathrm{n}=32)\end{array}$ & $\begin{array}{c}\text { Severe prolapse } \\
(\mathrm{n}=46)\end{array}$ & P-value \\
\hline LAD score (point) & $8.19 \pm 2.92$ & $13.33 \pm 2.49$ & $<0.001$ \\
LAD & & & $<0.001$ \\
$\quad$ Mild deficiency & $10(31.3)$ & $0(0)$ & \\
Moderate deficiency & $20(62.5)$ & $17(37.0)$ & \\
Severe deficiency & $2(6.3)$ & $29(63.0)$ & \\
LAM avulsion & $3(9.4)$ & $21(45.7)$ & $<0.001$ \\
MLH (cm²) & $14.95 \pm 2.60$ & $17.91 \pm 2.74$ & $<0.001$ \\
Pelvic floor disorders & & & \\
Rectocele & $20(62.5)$ & $33(71.7)$ & 0.390 \\
Enterocele & $0(0.0)$ & $3(6.5)$ & 0.265 \\
Cystocele & $2(6.3)$ & $9(19.6)$ & 0.097 \\
Internal intussusception & $21(65.6)$ & $29(63.0)$ & 0.815 \\
Anismus & $10(31.3)$ & $10(21.7)$ & 0.344 \\
\hline
\end{tabular}

Values are presented as mean \pm standard deviation or number (\%).

LAD, levator ani deficiency; LAM, levator ani muscle; MLH, minimal levator hiatus.

4.50 vs. $11.23 \pm 3.21, \mathrm{P}=0.001)$, FISI $(18.45 \pm 16.45$ vs. $30.56 \pm$ $19.24, \mathrm{P}=0.024)$, and Wexner constipation score $(8.24 \pm 6.66$ vs. $12.95 \pm 5.28, \mathrm{P}=0.022$ ) were significantly severe (Table 1 ).

The $3 \mathrm{D}$ pelvic floor ultrasound results are presented in Table 2. The mean LAD score was significantly higher in the severe prolapse group $(13.33 \pm 2.49$ vs. $8.19 \pm 2.92, \mathrm{P}<0.001)$, and the rate of severe deficiency was also significantly higher in the severe prolapse group (29 [63.0\%] vs. 2 [6.3\%], $\mathrm{P}<0.001)$. In addition, in the severe prolapse group, there were statistically significant differences in the rate of LAM avulsion (21 [45.7\%] vs. 3 [9.4\%]), and due to this, the mean MLH was also significantly larger (17.91 \pm $2.74 \mathrm{~cm}^{2}$ vs. $\left.14.95 \% \pm 2.60 \mathrm{~cm}^{2}, \mathrm{P}<0.001\right)$. However, there was no statistically significant difference between the 2 groups for pelvic floor disorders such as rectocele, enterocele, cystocele, internal intussusception, and anismus (Table 2).

Dividing each POP-Q stage, severe deficiency was only $6 \%$ in stage I but increased to $90 \%$ in stage IV. It can be seen that mild and moderate deficiencies decrease, and severe deficiencies increase as the stage increases (Fig. 2). In addition, both MLH and LAD scores tended to increase at each stage. The mean value of MLH was $14.41 \pm 2.94 \mathrm{~cm}^{2}$ in stage I, $15.57 \pm 2.08 \mathrm{~cm}^{2}$ in stage II, $16.98 \pm 1.96 \mathrm{~cm}^{2}$ in stage III, and $19.11 \pm 3.17 \mathrm{~cm}^{2}$ in stage IV, respectively. Also, the mean value of LAD score was $6.71 \pm 2.44$ in stage I, $9.87 \pm 2.53$ in stage II, $11.89 \pm 1.90$ in stage III, and $15.20 \pm 1.82$ in stage IV, respectively (Fig. 3).

\section{DISCUSSION}

In this study, it was confirmed that the MLH and LAD scores increased as the POP-Q stage increased. We divided patients with

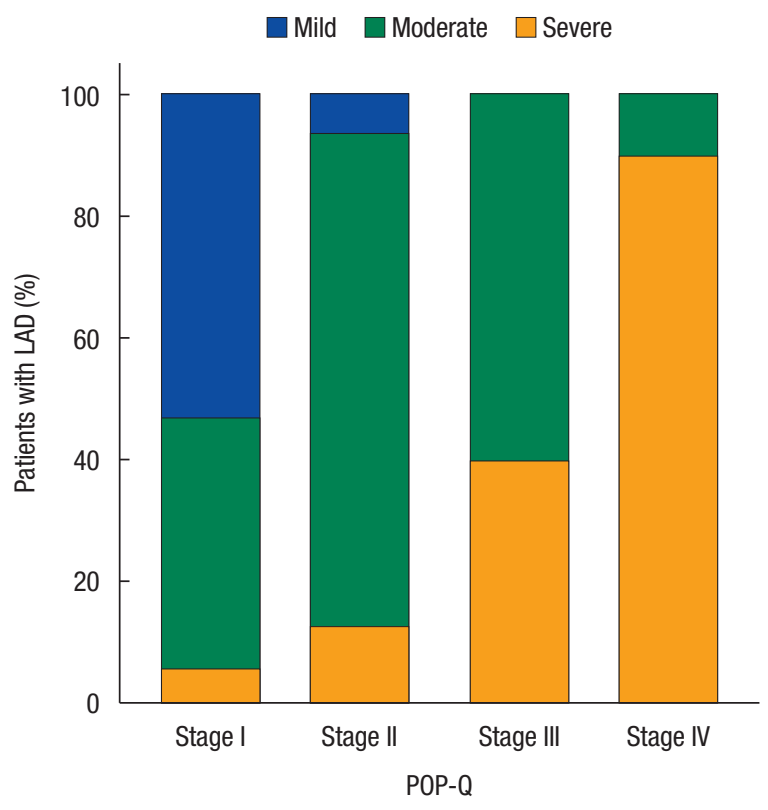

Fig. 2. Bar chart for the stages of prolapse and levator ani deficiency (LAD) frequency. The Y-axis denotes the percentile of patients with mild, moderate, or severe LAD. The X-axis denotes the stage of prolapse, as determined by the Pelvic Organ Prolapse Quantification staging system (POP-Q).

POP symptoms into a severe prolapse group with POP-Q grade 2 or higher and a mild prolapse group with less than POP-Q grade 2. This is because previous research has confirmed the association of LAM avulsion with anterior and middle compartment prolapse and significant prolapse defined as stage $\geq$ II [9]. Abdool et al. [29] reported significant associations between awareness and visualization of a vaginal lump in women with POP and LAM avulsion. The prevalence of LAM avulsion in women with pelvic floor disorders who presented to urogynecology units was reported to be $15 \%$ to $37 \%$ [30, 31]. Similarly, $30.8 \%$ of patients with prolapse who visited our pelvic floor clinic had LAM avulsion. In particular, in the severe prolapse group, LAM avulsion was found in up to $45.7 \%$ of patients. The levator hiatus is defined by the inferior pubic rami anteriorly and the ' $\mathrm{V}$ '-shape medial compartment of the LAM laterally and posteriorly. Because of this anatomical structure, LAM avulsion causes expansion of the MLH area and increases the LAD score. In the severe prolapse group, maximal resting pressure was significantly lower, but this was the result of including 2 patients with rectal prolapse and 4 patients with internal anal sphincter injury from previous anal fistula surgery.

There were many significant LAM deficiencies in the severe prolapse group at POP grades III and IV. There was no mild levator deficiency in the severe prolapse group, and severe levator deficiency was 6 times larger than that in the mild prolapse group. Rostaminia et al. [27] reported that moderate levator deficiency and severe levator deficiency were found to increase the odds for 

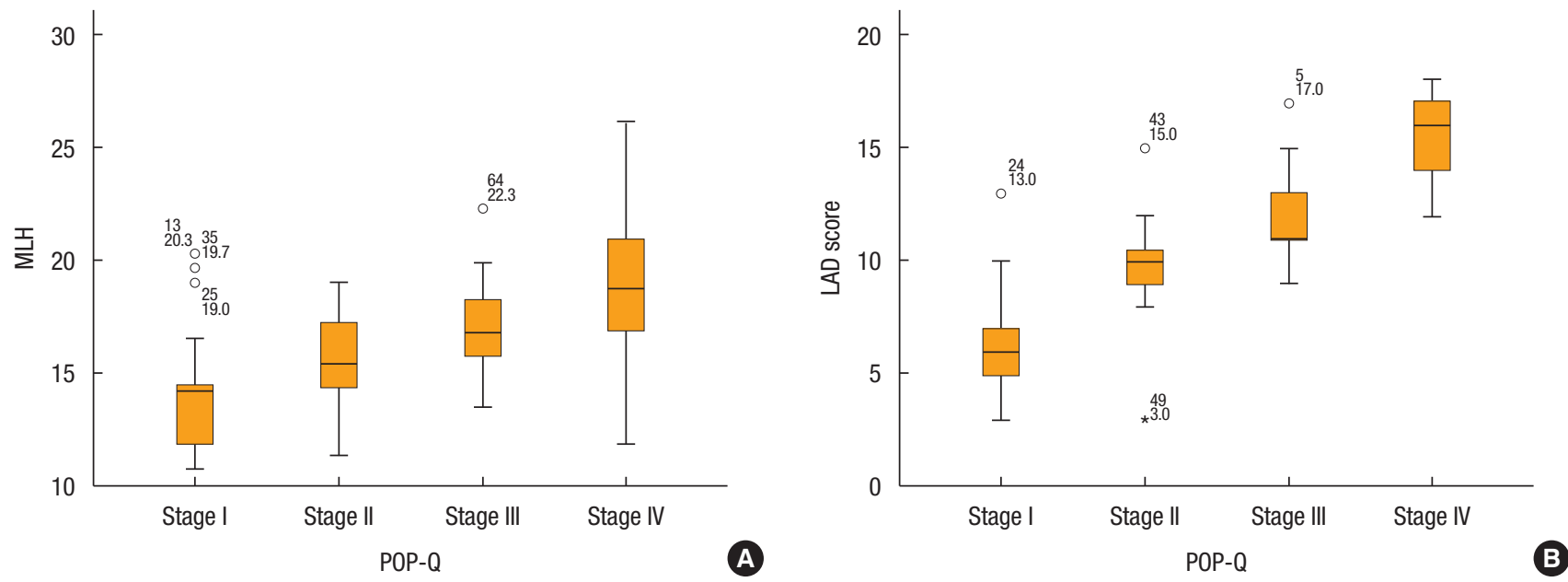

Fig. 3. Minimal levator hiatus (MLH) and levator ani deficiency (LAD) score according to Pelvic Organ Prolapse Quantification (POP-Q) stage. (A) Y-axis denotes the size of the MLH. The X-axis denotes the stage of prolapse as determined by the POP-Q staging system. (B) Y-axis denotes the score of LAD. The X-axis denotes the stage of prolapse, as determined by the POP-Q staging system.

POP 3.2 times and 6.4 times compared with mild deficiency. In the same study, the mean LAD scores of POP stages I, II, and IV were 8,10 , and 13; and in our data, the mean LAD scores of I, II, and IV were similar to those of 6, 9, and 15 [27]. In another study, the tomographic ultrasound imaging scales, expressed as a maximum score in the 6-point and 12-point, increased odds for a diagnosis of any significant POP on ultrasound 4.4 and 4.8 times, respectively [32]. Therefore, LAM deficiency is an important risk factor for POP, and it is essential to check the degree of LAM deficiency in the evaluation of POP patients.

Shobeiri et al. [25] performed 3D pelvic floor ultrasound on 80 nulliparous women without pelvic floor symptoms, measured the vaginal high-pressure zone, and calculated an average of $13.36 \pm$ $1.89 \mathrm{~cm}^{2}$. The MLH in our data was an average of $16.69 \pm 3.04$ $\mathrm{cm}^{2}$, and the reason is for women who gave parity (mean parity of $2.53 \pm 1.14$ times) and patients with POP symptoms. In particular, compared to the previous study, the mild prolapse group showed a small difference of $14.95 \pm 2.60 \mathrm{~cm}^{2}$, whereas the severe prolapse group showed a large difference of $17.91 \pm 2.74 \mathrm{~cm}^{2}$. This study was conducted on Asian women, and since the MLH area of Asian women was smaller than that of Caucasian women, it caused a small difference in the mild prolapse group. The MLH is the area between the LAM, through which the urethra, vagina, and rectum pass. Since the LAD score system is calculated using the PV and PA muscles, including the PR muscle, the MLH area increases as the LAD score increases, and as a result, POP occurs in a wider space.

Another important point was that there was no statistical difference, but anterior compartment prolapse such as cystocele occurred more frequently in the severe prolapse group (29 [63.0\%] vs. 2 [6.3\%], $\mathrm{P}=0.097)$. Avulsion, especially if bilateral, sometimes results in the transverse diameter being larger than the anterior- posterior diameter and is a major confounder and a strong risk factor for prolapse and prolapse symptoms [33]. Dietz and Simpson [9] reported that anterior and middle compartment prolapse is more related to LAM avulsion than posterior compartment prolapse. During avulsion, the PR muscle goes through the process of falling from the pubic ramus, and this part becomes the maximal transverse diameter, so avulsion appears more in anterior pelvic floor disorders. In our previous study, 3D pelvic floor ultrasound was useful as an initial test or screening method and for the diagnosis of posterior pelvic disorders [34]. Furthermore, ultrasound can also be used to diagnose LAM trauma, which is important when choosing treatment and informing patients, as women with major levator trauma are at an increased POP [35]. Several studies confirmed the reproducibility of the LAD of 3D ultrasound and showed good agreement between the intraobserver and interobserver $[36,37]$. Therefore, $3 \mathrm{D}$ pelvic floor ultrasound is a useful test for the diagnosis and assessment of POP as well as anterior and posterior pelvic floor disorders.

The POP-Q score is a limited method for diagnosing POP and reveals only clinical features. On the other hand, 3D pelvic floor ultrasound provides detailed information to understand the pathophysiology of POP. The major strength of the current study is that, rather than using an all-or-nothing scoring system, we used a scoring system that considers all the levator ani subdivisions. This provides more objective patient information than other examinations that express pelvic floor trauma as only unilateral or bilateral avulsions. However, this study had some important limitations. One limitation of this study is the small sample size, but despite having less than 40 women in each group, most of our findings and correlation were highly statistically significant and showed a large effect. Another limitation of the study was that the examiner was not blinded to the results of the differ- 
ent staging systems. However, in a previous study, no significant differences were found in this respect for the groups with and without blinding for the staging systems [13]. The last limitation is the cross-sectional study design, with no possibility of following the development of anatomical prolapse and symptoms over time. In conclusion, 3D pelvic floor ultrasound is an effective and valuable examination for the diagnosis of pelvic floor disorders, especially POP. There is a strong positive correlation between the POP-Q stages, the most widely used staging system, and the MLH and LAD scores can be seen in $3 \mathrm{D}$ pelvic floor ultrasound. The objective of this study was to objectively demonstrate LAM deficiency and MLH in women with POP are important contributions to this field. Future research should focus on the prevention and treatment of these levator ani deficiencies and the widening of the MLH to reduce the rate of POP later in life.

\section{CONFLICT OF INTEREST}

No potential conflict of interest relevant to this article was reported.

\section{REFERENCES}

1. Vergeldt TF, Weemhoff M, IntHout J, Kluivers KB. Risk factors for pelvic organ prolapse and its recurrence: a systematic review. Int Urogynecol J 2015;26:1559-73.

2. Wu JM, Matthews CA, Conover MM, Pate V, Jonsson Funk M. Lifetime risk of stress urinary incontinence or pelvic organ prolapse surgery. Obstet Gynecol 2014;123:1201-6.

3. Hallock JL, Handa VL. The epidemiology of pelvic floor disorders and childbirth: an update. Obstet Gynecol Clin North Am 2016;43:1-13.

4. Handa VL, Blomquist JL, Knoepp LR, Hoskey KA, McDermott KC, Muñoz A. Pelvic floor disorders 5-10 years after vaginal or cesarean childbirth. Obstet Gynecol 2011;118:777-84.

5. Dietz HP, Lanzarone V. Levator trauma after vaginal delivery. Obstet Gynecol 2005;106:707-12.

6. DeLancey JO, Morgan DM, Fenner DE, Kearney R, Guire K, Miller JM, et al. Comparison of levator ani muscle defects and function in women with and without pelvic organ prolapse. Obstet Gynecol 2007;109(2 Pt 1):295-302.

7. Caudwell-Hall J, Kamisan Atan I, Martin A, Guzman Rojas R, Langer S, Shek K, et al. Intrapartum predictors of maternal levator ani injury. Acta Obstet Gynecol Scand 2017;96:426-31.

8. DeLancey JO, Kearney R, Chou Q, Speights S, Binno S. The appearance of levator ani muscle abnormalities in magnetic resonance images after vaginal delivery. Obstet Gynecol 2003;101:4653.

9. Dietz HP, Simpson JM. Levator trauma is associated with pelvic organ prolapse. BJOG 2008;115:979-84.

10. Handa VL, Blomquist JL, Roem J, Muñoz A, Dietz HP. Pelvic floor disorders after obstetric avulsion of the levator ani muscle.
Female Pelvic Med Reconstr Surg 2019;25:3-7.

11. Handa VL, Blomquist JL, Roem J, Muñoz A, Dietz HP. Levator morphology and strength after obstetric avulsion of the levator ani muscle. Female Pelvic Med Reconstr Surg 2020;26:56-60.

12. Bump RC, Mattiasson A, Bø K, Brubaker LP, DeLancey JO, Klarskov P, et al. The standardization of terminology of female pelvic organ prolapse and pelvic floor dysfunction. Am J Obstet Gynecol 1996;175:10-7.

13. Dietz HP, Haylen BT, Broome J. Ultrasound in the quantification of female pelvic organ prolapse. Ultrasound Obstet Gynecol 2001; 18:511-4.

14. Dietz HP, Kamisan Atan I, Salita A. Association between ICS POP-Q coordinates and translabial ultrasound findings: implications for definition of 'normal pelvic organ support'. Ultrasound Obstet Gynecol 2016;47:363-8.

15. Broekhuis SR, Hendriks JC, Fütterer JJ, Vierhout ME, Barentsz JO, Kluivers KB. Perineal descent and patients' symptoms of anorectal dysfunction, pelvic organ prolapse, and urinary incontinence. Int Urogynecol J 2010;21:721-9.

16. Rodrigues AA Jr, Bassaly R, McCullough M, Terwilliger HL, Hart $S$, Downes K, et al. Levator ani subtended volume: a novel parameter to evaluate levator ani muscle laxity in pelvic organ prolapse. Am J Obstet Gynecol 2012;206:244.

17. Clark NA, Brincat CA, Yousuf AA, Delancey JO. Levator defects affect perineal position independently of prolapse status. Am J Obstet Gynecol 2010;203:595.

18. Dietz HP. Why pelvic floor surgeons should utilize ultrasound imaging. Ultrasound Obstet Gynecol 2006;28:629-34.

19. Majida M, Braekken I, Bø K, Benth J, Engh M. Anterior but not posterior compartment prolapse is associated with levator hiatus area: a three- and four-dimensional transperineal ultrasound study. BJOG 2011;118:329-37.

20. Lewicky-Gaupp C, Yousuf A, Larson KA, Fenner DE, Delancey JO. Structural position of the posterior vagina and pelvic floor in women with and without posterior vaginal prolapse. Am J Obstet Gynecol 2010;202:497.

21. Agachan F, Chen T, Pfeifer J, Reissman P, Wexner SD. A constipation scoring system to simplify evaluation and management of constipated patients. Dis Colon Rectum 1996;39:681-5.

22. Rockwood TH, Church JM, Fleshman JW, Kane RL, Mavrantonis C, Thorson AG, et al. Fecal Incontinence Quality of Life Scale: quality of life instrument for patients with fecal incontinence. Dis Colon Rectum 2000;43:9-16.

23. Shobeiri SA, LeClaire E, Nihira MA, Quiroz LH, O’Donoghue D. Appearance of the levator ani muscle subdivisions in endovaginal three-dimensional ultrasonography. Obstet Gynecol 2009;114:6672.

24. Bordeianou LG, Carmichael JC, Paquette IM, Wexner S, Hull TL, Bernstein $\mathrm{M}$, et al. Consensus statement of definitions for anorectal physiology testing and pelvic floor terminology (revised). Dis Colon Rectum 2018;61:421-7.

25. Shobeiri SA, Rostaminia G, White D, Quiroz LH. The determi- 
nants of minimal levator hiatus and their relationship to the puborectalis muscle and the levator plate. BJOG 2013;120:205-11.

26. Morgan DM, Cardoza P, Guire K, Fenner DE, DeLancey JO. Levator ani defect status and lower urinary tract symptoms in women with pelvic organ prolapse. Int Urogynecol J 2010;21:47-52.

27. Rostaminia G, White D, Hegde A, Quiroz LH, Davila GW, Shobeiri SA. Levator ani deficiency and pelvic organ prolapse severity. Obstet Gynecol 2013;121:1017-24.

28. Dietz HP, Bernardo MJ, Kirby A, Shek KL. Minimal criteria for the diagnosis of avulsion of the puborectalis muscle by tomographic ultrasound. Int Urogynecol J 2011;22:699-704.

29. Abdool Z, Dietz HP, Lindeque BG. Prolapse symptoms are associated with abnormal functional anatomy of the pelvic floor. Int Urogynecol J 2017;28:1387-91.

30. Steensma AB, Konstantinovic ML, Burger CW, de Ridder D, Timmerman D, Deprest J. Prevalence of major levator abnormalities in symptomatic patients with an underactive pelvic floor contraction. Int Urogynecol J 2010;21:861-7.

31. Dietz HP, Steensma AB. The prevalence of major abnormalities of the levator ani in urogynaecological patients. BJOG 2006;113: 225-30.

32. Trutnovsky G, Kamisan Atan I, Ulrich D, Martin A, Dietz HP. Levator ani trauma and pelvic organ prolapse: a comparison of three translabial ultrasound scoring systems. Acta Obstet Gynecol Scand 2016;95:1411-7.

33. Dietz HP, Franco AV, Shek KL, Kirby A. Avulsion injury and levator hiatal ballooning: two independent risk factors for prolapse? An observational study. Acta Obstet Gynecol Scand 2012;91:2114.

34. Jeong HY, Yang SJ, Cho DH, Park DH, Lee JK. Comparison of 3-dimensional pelvic floor ultrasonography and defecography for assessment of posterior pelvic floor disorders. Ann Coloproctol 2020;36:256-63.

35. Model AN, Shek KL, Dietz HP. Levator defects are associated with prolapse after pelvic floor surgery. Eur J Obstet Gynecol Reprod Biol 2010;153:220-3.

36. Braekken IH, Majida M, Ellstrøm-Engh M, Dietz HP, Umek W, $\mathrm{B} ø \mathrm{~K}$. Test-retest and intra-observer repeatability of two-, threeand four-dimensional perineal ultrasound of pelvic floor muscle anatomy and function. Int Urogynecol J Pelvic Floor Dysfunct 2008;19:227-35.

37. Majida M, Braekken IH, Umek W, Bø K, Saltyte Benth J, Ellstrøm Engh M. Interobserver repeatability of three- and four-dimensional transperineal ultrasound assessment of pelvic floor muscle anatomy and function. Ultrasound Obstet Gynecol 2009;33:56773. 